\title{
Subjetivación de la blanquitud por jóvenes universitarios: un estudio comparativo
}

\author{
Vanessa Ortiz-Piedrahíta, Ph.D.
}

Universidad del Valle, Colombia*

\section{Resumen (analítico)}

Este trabajo se inscribe en los estudios interdisciplinarios y decoloniales sobre la blanquitud. Describe la construcción subjetiva de la identidad blanca por jóvenes universitarios de Brasilia y Medellín, ello a partir de categorías que se interrelacionan, como la clase social, la etnicidad y la raza. Por medio de un abordaje metodológico cualitativo y comparativo se logró captar el universo significativo de los participantes. Finalmente, se presentan algunas reflexiones sobre el proceso performativo, y a veces contradictorio, que implica el reconocerse a través de los valores y privilegios que otorga la blanquitud en espacios tanto académicos como extracurriculares.

\section{Palabras clave}

Juventud, blanco, universidad, identidad.

\section{Thesauro}

Tesauro de Ciencias Sociales de la Unesco.

\section{Para citar este artículo}

Ortiz-Piedrahíta, V. (2020). Subjetivación de la blanquitud por jóvenes universitarios: un estudio comparativo. Revista Latinoamericana de Ciencias Sociales, Niñez y Juventud, 18(1), 1-24. http://dx.doi.org/10.11600/1692715x.18109

\section{Historial}

Recibido: 25.01.2019

Aceptado: 04.03.2019

Publicado: 09.12.2019

\section{Información artículo}

Artículo producto de la investigación titulada «La construcción identitaria de la blanquitud: sentidos y experiencias de jóvenes universitarios de clase media de Brasilia y Medellín». Trabajo financiado por Capes-Brasil 04.02.2015-30.01.2019. Área: Ciencias Sociales; subárea: Estudios comparados sobre las Américas. 


\title{
Subjective construction of whiteness by Young university students: \\ a comparative study
}

\begin{abstract}
(analytical)
This article forms part of interdisciplinary and colonial studies on whiteness and uses interrelated categories such as social class, ethnicity and race to explore the subjective construction of whiteness by young university students in Brasilia and Medellín. Based on a qualitative and comparative methodological approach, it was possible to capture the significant universe of university students who participate in the study. The author presents reflections and conclusions on the performative and sometimes contradictory process that implies recognizing oneself through the values and social privileges of whiteness in academic and extra-curricular spaces.
\end{abstract}

Keywords

Youth, white, university, identity.

\section{Subjetivação da branquitude em jovens universitários: um estudo comparativo}

Resumo (analítico)

O artigo faz parte dos estudos interdisciplinares e de-coloniais sobre a branquitude e descreve, a partir de categorias inter-relacionadas como classe social, etnia e raça, a construção subjetiva da branquitude de jovens universitários de Brasília e Medellín. A partir de uma abordagem metodológica qualitativa-comparativa, foi possível estudar o universo significativo dos universitários que fizeram parte da pesquisa. Finalmente, são apresentadas algumas reflexões e conclusões sobre o processo performativo e às vezes contraditório que implica reconhecer-se através dos valores e privilégios sociais da blanquitude hegemônica em espaços acadêmicos e extracurriculares.

Palavras-chave

Jovem, branco, universidade, identidade.

Información autora

[*] Socióloga egresada de la Universidad del Valle. Magíster en Psicología. Doctora en Ciencias sociales (Departamento de Estudos Latino-Americanos [ELA], Universidade de Brasilia). (iD) 0000-0003-4698-7050.

Índice H5: 2. Correos electrónicos: ortizvanessa9@gmail.com; vanessa.ortiz.piedrahita@correounivalle.edu.co 


\section{Introducción}

Uno de los objetivos del presente trabajo es repensar las relaciones raciales brasileñas y colombianas a partir del estudio de la subjetivación de la identidad blanca por estudiantes de la Universidad de Antioquia (Colombia) y de la Universidad de Brasilia (Brasil). Se trata de instituciones públicas de educación superior caracterizadas por ser pioneras en la implementación de acciones afirmativas o políticas de cuotas raciales en Latinoamérica. Precisamente en estos espacios los estudiantes han tenido la oportunidad de afirmar o resignificar sus «blanquitudes», ya que los discursos multi e interculturales, la politización de algunos grupos afrodescendientes e indígenas en estas naciones y las políticas antirracistas (como las cuotas raciales instauradas en los últimos años) ${ }^{1}$ no solo han impacto la subjetividad de las personas negras e indígenas, sino que también han obligado a que los blancos-mestizos se interroguen sobre el lugar social que ocupan. Desde esta perspectiva, los sentidos y los procesos de construcción de identidad de jóvenes en espacios escolares se construyen en diálogo con las políticas educativas ya instauradas y con los procesos de globalización cultural (Molina-Chávez \& Oliva-Figueroa, 2015).

Las investigaciones que se han enfocado en estudiar las desigualdades sociales y sus procesos identitarios en las Américas se han centrado en analizar las poblaciones indígenas y negras, para señalar el lugar subordinado que históricamente estas comunidades han ocupado en la jerarquía sociorracial desde el periodo colonial hasta la actualidad (Quijano, 2004; Wade, 1997). En el campo de las ciencias sociales, la blanquitud, como categoría étnico-racial, se ha estudiado poco debido a su falta de enunciación social, pero también debido a su investidura como categoría «neutral»o «normal».

${ }^{1}$ Las acciones afirmativas son políticas que buscan beneficiar a un sector o grupo social cuyos derechos han sido históricamente vulnerados y que, por tanto, necesitan de políticas o de medidas para remediar las condiciones de marginación estructural en las que viven. Por tanto, las acciones afirmativas suponen un ejercicio de discriminación positiva. Por ejemplo, las acciones se pueden expresar en cuotas raciales para el ingreso a la universidad, o como cuotas de representación en algunos cargos del Gobierno nacional. Estas acciones o cuotas no se limitan solo a los afrodescendientes o indígenas, sino que también pueden enfocarse en grupos «minoritarios» o «subalternizados» (Restrepo, 2013). 
Los estudios sobre la blanquitud comienzan a realizarse en Estados Unidos en la década de los noventa, y enseguida se empieza a trabajar en esta línea de investigación en países como Sudáfrica, Australia y Brasil (Cardoso, 2010). En el contexto latinoamericano, específicamente en países como Brasil y Colombia, los estudios sobre la blanquitud pueden calificarse de precursores. Autores como Bento (2003), Cardoso (2010), Piza (2002), Sovik (2004) y Viveros (2010) han intentado visibilizar este tipo de investigaciones. Según los mencionados autores, la blanquitud puede considerarse como un lugar de enunciación que denota privilegios simbólicos desde pasadas épocas hasta el presente. Así, se está hablando de una categoría histórica y relacional, es decir, que se ha construido en oposición a otras identidades étnico-raciales en las Américas.

Por otro lado, es posible interpretar la blanquitud como una estética corporal hegemónica (relacionada con un color de piel «claro» y rasgos fenotipos de las poblaciones anglosajonas $)^{2}$ y como una ideología de poder a partir de la cual se comprenden los fenómenos humanos, ya que conduce los valores de las poblaciones blancas hacia el centro de las representaciones que organizan el mundo. La blanquitud, por ende, forma parte de un discurso identitario que, aunque no es nominado patentemente entre las categorías étnicas y raciales (como en el caso de los grupos indígenas o afrodescendientes que reivindican sus identidades políticamente), está presente en la cotidianidad (Frankenberg, 2004; Sovik, 2004).

Cabe señalar que en Latinoamérica históricamente las clasificaciones basadas en el color de piel han sido el centro de la estratificación social. Parafraseando a Telles (2014), las pigmentocracias latinoamericanas han jerarquizado históricamente a las personas a partir de sus fenotipos y condiciones étnicas. En estas naciones, la blanquitud aún se erige como un ideal que se valora, tanto en el cuerpo como en la sociedad, lo cual genera continuas formas de discriminación (Moraes \& Paixão, 2014; Urrea et al., 2014).

Si bien hoy muchas instituciones y personas prefieren obviar el tema o no hablar sobre racismo, es menester señalar que en las naciones que promulgan la multi e interculturalidad se reavivan neorracismos de carácter sutil o, incluso, de manera institucionalizada. La tendencia actual del blind skin —o «ceguedad del color de piel» en palabras de Bonilla-Silva, 2015 - ha facilitado la invisibilización de los privilegios de las personas blancas, ya que se presenta una tendencia a considerar los hechos racistas como fenómenos

2 Sin embargo, no se trata de estudiar la blanquitud desde una perspectiva biológica, sino de entender las valoraciones simbólicas que sobre el fenotipo se han realizado históricamente. 
aislados o como exageraciones de las personas no blancas. De este modo, se ocultan las jerarquizaciones étnico-raciales y, simultáneamente, las desigualdades sociales que producen.

Si bien muchas investigaciones en las Américas se han dedicado a demostrar los constructos sociales que marcan la diferencia de los cuerpos de «color», pocos trabajos se han enfocado en estudiar la subjetivación identitaria de la blanquitud por los jóvenes universitarios en países como Colombia y Brasil. En la actualidad los jóvenes constituyen un grupo de gran importancia para analizar las construcciones racializadas, ya que han sido socializados en el marco de políticas multiculturalistas que tienen como objetivo el reconocimiento de las diferencias y de las identidades culturales, ello a fin de promover la no discriminación por razones de raza o de diferencia cultural (Giménez, 2010).

Investigaciones como la de Telles y Flores (2013) han señalado que gracias a las políticas multiculturales (leyes pautadas para gobernar o administrar la diversidad cultural), en Latinoamérica muchas personas jóvenes y con altos niveles educativos (quienes fenotípicamente podrían caracterizarse como blancos) prefieren autoidentificarse como personas pardas, mestizas o negras. ${ }^{3}$ Este dato es curioso, ya que en los censos de décadas pasadas su autoidentificación como blancos fue mayor (Loveman \& Muniz, 2007).

Hoy en día los jóvenes representan no solo un grupo etario y social importante para la sociedad — por sus posibilidades de agencia y transformación social_, sino también uno de los más importantes recursos de análisis social, debido a sus posicionamientos generalmente contrahegemónicos (Arango, 2006; Margulis \& Urresti, 1998). Por tal razón, resulta interesante conocer qué ocurre con aquellos jóvenes que hoy se autoidentifican como blancos. Quizá construyen blanquitudes acríticas (racistas) o blanquitudes críticas, es decir, no racistas e inclusivas con el diálogo multi e intercultural actual. ${ }^{4}$

3 Según datos del Instituto Brasileño de Geografía y Estadística, la población que en Brasil se declaró blanca cayó del 53.7\%, en el año 2000, al 47.4\% en el 2010 (91 millones de brasileños blancos). Por otro lado, según investigaciones como el proyecto Perla, desarrollado en Colombia en el 2010, la identificación como negro o afrodescendiente aumentó radicalmente, en contraste con años pasados. Esta situación demuestra el descenso de la identificación como blanco-mestizo en estos contextos.

4 El multiculturalismo busca la deconstrucción de los centros de poder colonial y la destrucción de los discursos racistas y excluyentes, enfatizando que el problema de nuestras sociedades no es la diferencia racial ni étnica, sino la obsesión por homogeneizar a todos los ciudadanos de un mismo contexto nacional. La mayoría de países latinoamericanos empezó a implementar políticas multiculturales después de los noventa, mediante sus cartas constitucionales. No obstante, autores como Walsh (2007) prefieren hablar de interculturalismo, entendiendo que las propuestas interculturales serían más equitativas (al menos en sus principios participativos, ya que no seguirán las lógicas hegemónicas capitalistas y blancas mestizas). 
Así pues, se plantea la siguiente pregunta de investigación: ¿cuáles son los sentidos, significados, experiencias o performances que construyen los jóvenes universitarios de clase media de la Universidad de Brasilia y de la Universidad de Antioquia 5 sobre su autopercepción de identidad como personas blancas? Se trata de estudiar la subjetivación de la blanquitud a partir de categorías que se entrecruzan, como clase social, etnicidad y raza.

\section{Metodología}

La investigación se realizó a partir de una metodología cualitativa de carácter descriptivo, interpretativo y comparativo. Se trata de un problema de indagación que se abordó desde una perspectiva multidisciplinar en el campo de las ciencias sociales. En términos epistemológicos, el estudio se nutrió de la perspectiva decolonial con el objetivo de visibilizar y resignificar las estructuras e ideologías sociales de dominación que se siguen expresando a través de categorías como etnicidad, raza y clase social en la región latinoamericana.

El proceso de selección de informantes implicó, en términos prácticos, o metodológicos, las siguientes consideraciones o criterios de inclusión: ${ }^{6}$

a. Los y las jóvenes universitarios involucrados en el proceso investigativo participaron por iniciativa propia.

b. Solo se tuvo en cuenta a aquellos jóvenes (hombres y mujeres) que en el marco de la investigación se autoidentificaron como blancos.

c. Se eligieron jóvenes de varios cursos o carreras universitarias de ambas universidades, con el objetivo de contrastar sus discursos y prácticas.

5 Por un lado, se destaca Medellín (sede de la Universidad de Antioquia) por la construcción racializada de su identidad regional. La cultura de Medellín, reconocida localmente como paisa, reivindica cierta pureza racial entendida como ausencia de mezclas con indígenas y negros (Viveros, 2010). Es posible que la identificación regional y nacional de este grupo poblacional, poseedor de ciertas cualidades asociadas a la blanquitud moderna (pujanza, creatividad, honestidad, laboriosidad, emprendimiento) les haya proporcionado cierto éxito económico y político en el contexto colombiano (Melo, 1988). Por otro lado, el plano piloto de la ciudad de Brasilia, aunque no promulga abiertamente una identidad racial «pura y superior», está habitado en mayor proporción por individuos blancos-mestizos, que son los mayores monopolizadores del poder económico y político en la ciudad (Abramo \& Branco, 2004).

6 Se consideraron los siguientes criterios de exclusión: estudiantes que se autorreconocen no blancos (indígenas, afrodescendientes, mulatos, zambos, etc.), estudiantes que se negaron a participar en la investigación y estudiantes de otras universidades y ciudades tenidas en cuenta en los criterios de inclusión. Además, por cuestiones de privacidad y ética, se cambiaron los nombres de los estudiantes. 
d. Se dio prioridad a jóvenes oriundos de Medellín o que hubieran pasado la mayor parte de su vida en esta ciudad.

e. Se eligieron jóvenes oriundos de Brasilia o que hubieran vivido la mayor parte de su vida en esta ciudad.

f. Participaron en la investigación jóvenes de clase media. Aparte de los capitales materiales y económicos que pueda tener una familia o persona, es necesario tener en cuenta aspectos como el habitus adquirido, es decir, los gustos, valores y el consumo que forman estilos de vida y funcionan también como dispositivos enclasantes. Así pues, se optó por una definición de clase más holística, como la propuesta por Bourdieu (1998).

g. Se entrevistó a dieciocho estudiantes en ambas universidades. En la Universidad de Antioquia (en adelante UdeA) se entrevistó a tres hombres y seis mujeres, Mientras que en la Universidad de Brasilia (en adelante UnB) se tuvo en cuenta a cinco hombres y cuatro mujeres. No obstante, es necesario aclarar que se utilizó la idea de saturación cualitativa; esto es, en términos metodológicos se realizaron las entrevistas necesarias hasta que se consideró que el material recolectado fue suficiente en términos empíricos.

La información se recolectó por medio de entrevistas semiestructuradas y observaciones constantes de campo durante aproximadamente un año. Las entrevistas semiestructuradas indagaron aspectos relacionados con la blanquitud en términos subjetivos y sociales, pero ello no implicó un diálogo rígido entre investigadora y estudiantes. De hecho, se privilegió la voz de los y las estudiantes, y la dinámica que estos le dieron a la actividad. Las entrevistas se realizaron en varias ocasiones a una misma persona, con el objetivo de complementar la información requerida.

En cuanto a la observación, cabe señalar que se realizó tanto en los contextos educativos (campus universitarios) como en espacios extracurriculares: centros comerciales, bares, calles de las ciudades y sitios de encuentro deportivo, entre otros. Las observaciones se hicieron con consentimiento informado (es decir, que las personas involucradas tenían conocimiento de la actividad) y se realizaron de la manera más cotidiana e informal, ya que se me permitió compartir algunos de sus espacios de socialización y de vida de manera flexible, amistosa y cercana. Finalmente, por medio de Atlas.ti ${ }^{\mathrm{TM}}$ se organizó la información procedente de las entrevistas, agrupándola en las siguientes catego- 
rías: blanquitudes críticas o alternativas, blanquitudes mestizas y blanquitudes acríticas.7 En particular, los discursos recolectados en las entrevistas se interpretaron a la luz de fuentes documentales y teóricas provenientes de los estudios decoloniales y los whiteness studies. Además, la información se analizó mediante varias matrices de observación, en las que se registraron algunos de los principales hábitos y prácticas de los estudiantes, tanto en las respectivas instituciones educativas como en diversos espacios extracurriculares. En suma, se interpretó la información mediante un diálogo que se construyó con los datos empíricos — que fueron tanto escuchados como observados- y el marco teórico que guío la investigación.

\section{Resultados}

\section{Sentidos y significados sobre la blanquitud}

¿Qué significa ser blanco? Este es un asunto difícil de explicar. Para la mayoría de las y los jóvenes blancos(as) entrevistados, tal pregunta resultó sorpresiva, debido a la naturalización que experimentan de su propia blanquitud en términos fenotípicos y simbólicos. Al parecer, las personas negras están más acostumbradas a visibilizar su condición racial y étnica, bien sea por cuestiones políticas, institucionales o de autoafirmación personal. En contraste, las personas blancas nunca han necesitado declarar, o siquiera reflexionar, sobre su propio ser, dadas la normativa y la hegemonía de dicha investidura (Fanon, 1968; Ware, 2004).

Las interpretaciones y los sentidos que una persona elabora sobre su condición de blanco variarán según sus experiencias de vida como sujeto racializado en órdenes estrictamente jerarquizados, como los de las Américas. Además, estas experiencias subjetivas son moldeadas por las condiciones de clase, nacionalidad o sexo con las cuales se identifique el individuo.

7 Surgen otras categorías que no se trabajan en este artículo, debido a las restricciones que impone su extensión. Cabe señalar que el recurso analítico de las blanquitudes acríticas o críticas es un constructo teórico elaborado por Cardoso (2010) y por otros investigadores, cuyos trabajos hacen parte de los whiteness studies. Se usó en el marco de la indagación a manera de lentes interpretativos de la realidad empírica, pero esto no quiere decir que signifique o represente de manera exacta la realidad de los estudiantes que participaron en el estudio. Por tal razón, se habla simplemente de una tendencia hacia uno u otro tipo de blanquitudes, con lo cual no se pretende encasillar o esencializar. 
Ser blanco es simplemente tener un color de piel «claro»; ser blanco implica tener privilegios sociales; ser blanco significa «ser un humano normal o corriente». Estas fueron algunas de las respuestas de los y las estudiantes de ambas universidades. No obstante, y para ser fieles a la voz de aquellos sujetos participantes en la investigación, se resaltarán a continuación las posiciones más representativas sobre el tema:

Para mí, ser blanca significa tener una serie de privilegios sociales, y por eso la persona que es morena quiere ser blanca. Aunque en mi familia tenemos ascendencia italiana y europea, también hay ascendencia indígena; entonces, es muy difícil decir quién es blanco o no en el Brasil. (Dina, estudiante de Historia, UnB)

Creo que nunca me detuve a analizar qué significado tiene para mí el hecho ser blanca, o qué sentido le doy [silencio]. Creo que si la persona sufre discriminación, va a reflexionar sobre su color de piel o raza, pero si no sufre prejuicio racial o étnico, no va a reflexionar. (Eva, estudiante de Química, UnB)

Yo soy caucásico... superficialmente; o sea, blanco... No tan blanco como mis familiares, pero sí lo soy. Los blancos somos personas normales, regulares, pero a mí no me preocupa tanto definirme dentro de un grupo específico. Pero no puedo negar, por obvias razones, que soy blanco por mi color de piel. (Paulo, estudiante de Ingeniería de Materiales, UdeA)

Los y las jóvenes entrevistados de la UdeA coinciden con los estudiantes de la UnB al establecer que la blanquitud, tanto corpórea como étnica, denota privilegios y ventajas sociales. No se trata solo de una percepción meramente subjetiva, sino de una cuestión estructural, ya que las ciudades de Medellín y Brasilia están organizadas a partir de la lógica de la blanquitud hegemónica. Así pues, las personas que viven en mejores condiciones económicas en ambas ciudades generalmente son blancas. No obstante, esta situación no es exclusiva de dichas urbes, sino de la mayoría de las ciudades e instituciones de educación superior en Colombia y Brasil, en donde las personas mestizas-blancas siguen siendo las que monopolizan el poder político, económico y educativo. En palabras de Lourdes (estudiante de Física en la UdeA), «incluso en el contexto de la universidad puedes observar que las personas de apariencia más blanca son las que están en las mejores carreras de la universidad, como Medicina, y son las que viven en los mejores barrios de la ciudad».

Cuando se habla de privilegios de la blanquitud se está haciendo referencia a las ventajas que tienen los individuos identificados como blancos en sociedades en las que la estratificación racial y étnica fue y sigue siendo un elemento constitutivo de su organización estructural (Frankenberg, 1993). En palabras de Sovik (2004), la blanquitud brin- 
da a las personas privilegios sociales desde el nacimiento, ya que la blanquitud está relacionada con valores positivos como inteligencia, belleza, moralidad y civilidad; estas son representaciones que las personas interiorizan y reproducen en su cotidianidad, salvaguardando así a las personas calificadas o nominadas como blancas de actos que las ubique en una posición subalterna. Por tal razón, es poco probable que una persona blanca desee cambiar o alterar su tono de piel u otras características atribuidas a su blanquitud. Así pues, es posible interpretar que las personas blancas entrevistadas no estén dispuestas a ceder tan fácilmente su posición de privilegio o preeminencia social.

Nunca he pensado que sería mejor cambiarme el color de ojos o de piel. Siempre quise ser más alta, pero eso no tiene que ver con mi identidad cultural o racial. (Luana, estudiante de Turismo, UnB)

Pienso que la diversidad física y cultural es perfecta, pero no por eso cambiaría de mí nada, pues soy consciente de que sufriría prejuicio o discriminación racial. (Carla, estudiante de Ciencias Naturales, UdeA)

En cuanto a la «normalidad» del blanco destacada por Paulo, investigadores como Bento (2003) y Grosfoguel (2008) interpretan que los blancos se vuelven sujetos propensos a ejercer actos racistas a la hora de asumir el principio biocéntrico de la definición del ser humano, puesto que a partir de la blanquitud se tiende a evaluar de manera decreciente las alteridades.

Conviene señalar que, tanto en Brasilia como en Medellín, el factor predominante de reconocimiento de la blanquitud hace alusión al color de piel. Si bien Echeverría (2007) establece que la blanquitud alude a la ética puritana del capitalismo y a la lógica del consumo actual que guía a las sociedades occidentales, en la mentalidad de los y las estudiantes entrevistados, la blanquitud se relaciona más con una cuestión fenotípica y de clase social. Una persona con un color de piel «relativamente claro» (así tenga ascendencia indígena o negra) y que tenga la posibilidad adquisitiva para adecuar el cuerpo o la apariencia según las lógicas estéticas y sociales dominantes, puede autorreconocerse y ser reconocido también por la alteridad, blanco. Por eso, en los discursos de los y las estudiantes se encuentran varias definiciones para autodescribirse o reconocerse, como las siguientes: «Yo me considero blanca extrablanca» (Luana, UnB), «blanco-leche» (Mario, UdeA), «blanco multicolor» (Marco, UnB), «yo soy blanco-mestizo quemado» (Gael, UdeA). Se trata de una clasificación poliforme que recibe múltiples nominaciones y sentidos. Por tanto, la blanquitud no denota un modo de clasificación homogéneo y siem- 
pre debe entenderse relacionada con otras categorías sociales (Frankenberg, 2004; McLaren, 2005). Parafraseando a Ware (2004), las identidades raciales raramente son estáticas, ya que se encuentran sujetas a presiones socioculturales continuas que contribuyen a moldear las distinciones producidas por las vicisitudes del pensamiento racial aún vigente en las sociedades contemporáneas. Eso quiere decir que, aunque a todos los estudiantes entrevistados pueda incluírselos en la etiqueta genérica blanco, dicha etiqueta está dividida en subcategorías llenas de sentidos particularizados. Se está hablando, entonces, de una blanquitud poliforme que se construye y se reconstruye en un diálogo continuo entre la propia biografía personal y las estructuras sociales vigentes.

De manera complementaria, en la observación adelantada en espacios extracurriculares, se encontró que la blanquitud de los y las estudiantes es reafirmada por la alteridad racial y de clase social. En varias ocasiones fue posible observar, en centros comerciales y restaurantes, cómo vendedores y meseros cuyos fenotipos podrían describirse como indígenas, zambos o negros, siempre tienden a dirigirse en primera medida al estudiante (hombre o mujer) con el fenotipo más claro o blanco del grupo. Así pues, en Medellín, igual que en Brasilia, la apariencia más blanqueada parece ser siempre reconocida como un indicador de mayor clase social o de mayor poder adquisitivo (observación corroborada por aquellos jóvenes que hicieron parte de la investigación). Por tanto, la blanquitud implica una construcción étnico-racial hegemónica y normativa que debe interpretarse de manera más integral, si se tiene en cuenta, al tiempo, la condición de clase social (imaginada o real) que a ella se atribuye.

\section{Blanquitud critica/alternativa}

Las blanquitudes críticas o alternativas serían las más flexibles y abiertas al diálogo y al entendimiento multicultural. Este tipo de blanquitudes son vistas como una oportunidad para acabar con el racismo vigente, pues la persona que se declara blanca desde esta perspectiva tiene interés en reflexionar sobre sus propios privilegios en el contexto social, situación que favorecería que este tipo de personas establezca relaciones más equitativas con la alteridad racial y étnica (Bouteldja, 2017; Cardoso, 2010).

Los actuales estudios poscoloniales y críticos de las ciencias sociales sobre la blanquitud señalan la necesidad de deconstruir ese concepto como una identidad racial y étnica hegemónica o «superior», con el objetivo de hacerla más apta para la configuración de una sociedad menos politizada y menos racista (Passos, 2013). 
En el contexto multi e intercultural contemporáneo, los movimientos étnicos, los grupos políticos y las instituciones educativas han hecho un gran esfuerzo por luchar contra las prácticas racistas, situación que no solo ha desembocado en la construcción de identidades más respetuosas con la alteridad, sino que ha propiciado que esas identidades cuestionen sus posiciones sociales. En consecuencia, expresar que «el blanco» es racista solo por ser «blanco» sería una esencialización y ontologización que no viene al caso. Obviamente, hay mayor probabilidad de que una persona considerada blanca ejerza actos racistas debido a su ubicación privilegiada en el orden sociorracial, pero también está en manos de las personas blancas deconstruir y resignificar los valores de superioridad en los que se ha fundado su identidad subjetiva y social. Por tanto, hay que tener en cuenta que el racismo solo se podría acabar si lo combatieran voluntariamente quienes lo han iniciado o están en una posición de poder (Schucman, 2012). De hecho, únicamente se podrían construir nuevos órdenes sociales si se acaba con los privilegios sociales que otorga la blanquitud, o al menos si se hace a las personas blancas más conscientes de tales privilegios. Por ejemplo, es factible que una persona blanca - en términos fenotípicos - no se identifique con la blanquitud étnica capitalista imperante en la actualidad (Dyer, 1997). Es el caso de algunas personas entrevistadas, que apoyan las políticas de cuotas raciales, o también el de muchos jóvenes blancos que prefieren el rap, el reggae y las prácticas religiosas procedentes de una matriz africana.

A mí me gustan estilos de música como el hip hop debido a las letras de crítica social que tienen, y también me gusta la comida bahiana, y apoyo los movimientos políticos negros que luchan por las desigualdades raciales y sociales. Creo que ser blanco no me impide identificarme con otras culturas, y tampoco me impide, por ejemplo, intervenir cuando veo algún tipo de discriminación. [...] Años atrás no pensaba mucho en eso, pero creo que el tiempo en una universidad como esta le ayuda a uno a construir otra forma de pensar. (Caio, estudiante de Química, UnB)

Particularmente pienso que ser blanco en realidad no lo imposibilita a uno para desmovilizarse de sus prioridades o comodidades. Yo apoyo políticas afirmativas de cuotas raciales para el ingreso de estudiantes indígenas a la universidad. Es más, pienso que en el ámbito laboral también deberían hacerse. (Mario, estudiante de Letras, UdeA)

Aunque me identifico como blanco de clase media y de familia católica, soy consciente del respeto por la diferencia. Por ejemplo, me parece interesante que no todo en un país sea tan homogéneo, y aquí en Brasil, que se practiquen religiones no católicas u otros ritmos musicales. Es lo que a mi parecer construye un país más diverso e importante. (Gabriel, estudiante de Derecho, UnB) 
Es posible interpretar que las reflexiones de las y los estudiantes blancos(as) se han construido gracias a la educación recibida - tanto en el medio académico como en el entorno familiar-y también se debe a la influencia de los discursos multiculturalistas, que han influido en su subjetividad. Así mismo, se destacan las elecciones que los estudiantes han tomado en el marco de sus propias historias de vida, donde ellos han logrado comprender no solo la posición subordinada de los grupos racializados (como negros o indígenas en Brasilia o Medellín) sino que también valoran el aporte cultural de estos grupos humanos a sus respectivos países, ciudades y universidades de carácter público.

La blanquitud crítica supone un modo subjetivo de identificación, pero también político, ya que no basta con declararse blanco antirracista: esta posición también supone una praxis social, puesto que finalmente todo lo político termina siendo personal. Desde esta perspectiva epistemológica, reconocerse blanco resulta realmente importante para establecer una verdadera equidad social. No se trata solo de reconocer los privilegios con que se cuenta: la idea principal es deconstruir la ideología hegemónica en la que se ha sustentado la supremacía racial blanca desde el periodo colonial hasta la actualidad (Dyer, 1997).

\section{Blanquitud acrítica/colonial}

Si la blanquitud crítica intenta visibilizar tal condición como hegemónica, para de este modo deconstruir su hegemonía y poder, la blanquitud acrítica significa todo lo opuesto, es decir, el intento que hacen algunas personas por autonominarse miembros de una raza «superior» (Cardoso, 2010). Se trata de una construcción identitaria que aún comulga con las ideologías coloniales y racistas.

Generalmente, cuando se va a definir la blanquitud, no se define a partir de su condición «homicida», en términos históricos (Baldwin, 1984). Por tanto, es necesario estudiar también a las personas blancas que históricamente han ejercido diferentes tipos de racismos simbólicos y prácticos sobre las personas calificadas como no blancas (Twinang, 2015).

Actualmente el crecimiento global de la ansiedad blanca se manifiesta en el cierre de fronteras y en la elección de gobernantes de ultraderecha, no solo en Europa, sino también en las Américas. De alguna manera los sentimientos de xenofobia se juntan con ideales nacionalistas y conservadores para promulgar nuevamente el levantamiento de una «blanquitud superior» (Bhambra, 2017). En el contexto capitalista, mediático y global del mundo contemporáneo, los problemas relacionados con la etnicidad y la raza se reavivan, creándose de este modo múltiples neorracismos, sutiles o evidentes (Mullings, 2013; Ortiz-Piedrahíta \& Tavolaro, 2015). Sobre el tema, las y los estudiantes entrevista- 
dos en ambas universidades rechazan los valores históricos de la superioridad racial blanca. Al respecto, algunos estudiantes expresaron lo siguiente:

Creo que esa ideología de superioridad racial blanca ha traído muchos problemas, no solo a los judíos, sino también a nosotros, en Latinoamérica [...], y claramente ya sería hora de superar estas ideas arcaicas. (Elena, estudiante de Odontología, UdeA) Es ridículo hablar de supremacía blanca en Brasil, o de nazistas, ya que sabemos que todos somos mezclados y venimos de diversos orígenes en este país: blanco, negro, indígena [...]. Entonces, realmente no veo el sentido a ese tipo de ideas o pensamientos. (Luiz, estudiante de Gestión Pública, UnB)

A pesar del rechazo generalizado que manifiestan los y las estudiantes de ambas universidades sobre actos de racismo blanco en el pasado o en la actualidad, en algunos de ellos se presenta una naturalización de la blanquitud que los hace inconscientes de sus prejuicios racistas en el ámbito personal y social. Por ejemplo, algunos estudiantes entrevistados argumentaron no estar conformes con las políticas de cuotas raciales en sus universidades, porque constituyen una ventaja no ganada por los grupos indígenas y negros. Para estos estudiantes, este tipo de políticas deberían abolirse, ya que se debería valorar «la competencia igualitaria».

No se debería permitir el favoritismo o ese tipo de políticas que revictimizan a los afro o indígenas y a sus familias, solo por una cuestión de color de piel o raza, sabiendo que todos tenemos las mismas capacidades. (Lourdes, estudiante de Física, UdeA)

Es difícil hablar sobre la política de cuotas raciales. Déjame ver... Yo estoy en contra, porque todo el mundo tiene capacidad de aprender y de adquirir conocimientos y, por ende, todo el mundo puede pasar en la universidad. No porque usted sea indígena o negro, su capacidad intelectual va a ser menor... Todo depende del esfuerzo y la disciplina personal para salir adelante y obtener éxito. (Luana, estudiante de Turismo, UnB)

Por otro lado, unos cuantos estudiantes recalcaron no sentir atracción por personas negras ni deseo de procrear hijos con ellas. Según los comentarios de los estudiantes, imaginarios como la pereza, la deshonestidad y una libido amoral asociados a su condición racial los hace propensos a engañar.

En mi familia dicen que los hombres negros son «perros». También dicen que los hombres negros son mujeriegos, y pues al ver todo lo que los novios negros les hacían a mis primas, empecé a interiorizar esa idea. A mí, por ejemplo, en la actualidad no me gustan los hom- 
bres negros. Siempre he tenido novios rubios o medio mestizos, como yo porque, aunque sé que eso puede ser un prejuicio, no puedo ir contra mis preferencias. (Lina, estudiante de Ciencias Naturales, UdeA)

Cuando yo era niño, al lado de mi casa vivía una familia negra, y mi abuela me decía en broma que yo me iba a casar con una negra, y yo, no sé por qué, me enojaba, y hoy en día no tengo preferencias íntimas por mujeres negras, pero no con ello quiero decir que sea racista, porque no lo soy. (Tulio, estudiante de Medicina, UnB)

Los anteriores prejuicios no racionalizados, aunque no llegan al plano de la promulgación pública, se asocian con las ideologías de superioridad cultural y racial blanca que se instauraron en tiempos de la colonización y se fortalecieron con las ideas positivistas sobre la raza en el siglo XIX (Frankenberg, 2004). Estas ideologías raciales situaron en el tope de la jerarquía la blanquitud, asociándola con valores positivos y, en contraste ubicaron las identidades no blancas en la base de la jerarquía, relacionando estas últimas con valores peyorativos como la pereza y la libido amoral. Estas ideas fueron reproducidas durante varios siglos por muchas familias mestizas en las Américas, con el objetivo de ir aclarando generacionalmente la descendencia o progenie (Wade, 1997). De hecho, algunas de las personas entrevistadas afirmaron que en sus propia familia (abuelos, tíos, tías) han escuchado tal prejuicio racial y, quizá por tal razón, ellos mismos de manera inconsciente han definido sus preferencias romántico-sexuales hacia los espectros más claros de la piel.

En suma, puede afirmarse que algunas estudiantes aún se siguen identificando con el polo de una blanquitud acrítica, es decir, poco reflexiva e inequitativa. Sin embargo, no se trata de racismos directos o violentos que atenten contra la integridad física de las personas no blancas, como pasa con los movimientos que están surgiendo en Estados Unidos en torno al Ku Klux Klan (La entrevista completa..., 2017), sino más bien trata de prejuicios subjetivados que no se aceptan públicamente, pero tienen un impacto práctico en la vida de los propios estudiantes y de sus pares, sean o no cercanos.

\section{Blanquitudes mestizas o criolizadas}

Quizás el mayor resultado de la investigación fue el de la blanquitud mestiza o criolizada, pues para el blanco latinoamericano es difícil separarse de la idea del mestizaje en las Américas; lo anterior, en tanto que, hoy más que nunca se valora y acepta el origen multicultural de estos países. Así pues, una persona, por más «blanca» o «clara» que sea en términos fenotípicos, con frecuencia reconocerá su ascendencia mestiza, mulata o ne- 
gra. Esta revalorización del origen no blanco del latinoamericano se debe a la influencia de las políticas multiculturalistas en la región, el esfuerzo de los movimientos políticos afro e indígenas por reivindicar sus culturas y corporalidad y, obviamente, a las acciones de los individuos racializados para ser reconocidos como sujetos de derechos (Urrea et al., 2014).

En el pasado la constante era negar cualquier ascendencia negra o indígena en las familias de clase alta y blanqueadas. A esto, Guerreiro-Ramos (1957) le llamaría la patología social del blanco brasileño. Pero hoy en día en Latinoamérica tiende a superarse ese prejuicio, y gracias al giro multicultural que se ha presentado desde finales de los ochenta del siglo XX hasta la actualidad, hay una valoración de los grupos étnicos no blancos, expresada en los censos, en los que la identificación como indígenas y negros ha aumentado radicalmente (Telles \& Flores, 2013). Así pues, la blanquitud mestiza del latinoamericano no es igual a la blanquitud del estadunidense o del europeo. Se trata de una resignificación y apropiación de esta ideología de superioridad racial y cultural, que se expresa en estos contextos geográficos e históricos de manera particular. Por ejemplo, cuando en Estados Unidos se habla de gente blanca, se hace referencia a los descendientes del norte de Europa (Alemania, Suiza, Holanda, Noruega, Dinamarca, etc.), quienes comparten prácticas y creencias religiosas (como las protestantes) y creen fielmente en un proyecto propio de nación y «liberal», que se gestó en el periodo de la Colonia y se unificó a partir del uso de una lengua común (el inglés). En Estados Unidos, los pueblos del sur de Europa, como los italianos, nunca fueron considerados «muy blancos», así como tampoco los judíos o los latinoamericanos. En Estados Unidos, por más blanqueado que sea el latinoamericano, en términos fenotípicos, nunca será reconocido como un «blanco real», debido a sus prácticas culturales (Montero, 2005). En contraste, en Latinoamérica es más importante la clasificación del color de piel en términos fenotípicos, pero este espectro de la blancura es más amplio que en otros espacios, ya que en algunos casos se acepta como blanco desde el mestizo-mestizo hasta el mestizo más blanqueado o claro.

Autores como Steyn (2014) argumentan que las blanquitudes criolizadas son identidades que no solo reproducen prácticas de los grupos blancos europeos, sino que de modo simultáneo reproducen prácticas de los grupos negros e indígenas. En esta misma línea de argumentación encontramos a Alves (2010), quien sostiene que en Brasil existe una blanquitud mestiza en la que se reconoce el origen multicultural y racial de la población, si bien se sigue reproduciendo el ideal de la blanquitud occidental. Así pues, las blanquitudes mestizas, criolizadas o glocales hacen referencia, tanto en Brasil como en Colombia, a blanquitudes heterogéneas que vinculan elementos propios y extranjeros. 
En el caso de los y las estudiantes, se encuentra realmente que todos, más que reproducir estrictamente los ideales de la blanquitud eurocéntrica descritos por Echeverría en su texto «Imágenes de la "blanquitud"» (2007), se presenta la mezcla, hibridación y reconocimiento de ambas partes. A pesar de ello, no hay que ocultar que existen representaciones sociales y significaciones subjetivas sobre la blanquitud mestiza que varían según el contexto histórico y cultural. Por ejemplo, en Brasil hay personas que aún interpretan la influencia alemana e italiana como símbolo de la blanquitud «real». Algunos estudiantes, como Caio, lo explican así:

Aquí, en Brasil, todos los blancos, por más claros que seamos, tenemos ascendencia mestiza; pero desde mi punto de vista, el blanco brasiliense, por ejemplo, es diferente del sur del Brasil, que tiene más influencia extranjera, sobre todo alemana e italiana, y eso se ve en sus comidas, los estilos de las casas y hasta en la música que escuchan. En cambio, el de aquí [de Brasilia] es blanco por su color de piel y gustos económicos, pero tiene más influencia nordestina [negra e indígena] en su actuar. (Caio, estudiante de Química, UnB)

Así las cosas, el ideal de blanquitud mestiza varía de región en región en un mismo país. En Colombia, a diferencia de Brasil, la influencia alemana e italiana en el periodo republicano no fue tan fuerte. Por tanto, en este país el ideal de blanquitud mestiza hace alusión a la ascendencia directa española y la mezcla entre indígenas y personas negras que en el periodo colonial fueron llevadas a la fuerza al territorio hoy conocido como Colombia.

Particularmente, en el contexto de Antioquia y Medellín, la blanquitud mestiza recuerda más la idea del arriero paisa (por encima del origen español e indígena), quien colonizó los territorios escarpados del departamento antioqueño desde el periodo colonial (Uribe, 1941). Hasta hoy, ese imaginario es representativo de la cultura antioqueña, ya que representa fuerza, disciplina, tenacidad y emprendimiento (Melo, 1988). La figura del arriero paisa ha logrado cohesionar a los ciudadanos antioqueños bajo un mismo ideal de emprendimiento capitalista, que representa los valores del blanqueamiento étnico-cultural. Por eso, a la hora de medir el progreso de las regiones colombianas, siempre se hace comparándolas con el departamento antioqueño o con las grandes ciudades del país. Así lo ejemplifican dos de los entrevistados:

Cuando me preguntas sobre el blanco antioqueño, inmediatamente me imagino el arriero paisa. Es decir, la berraquera que tenemos para el trabajo duro y la disciplina que viene de nuestros antepasados; pero también me imagino los reconocidos empresarios y emprendedores que hoy tenemos en la región. (Pablo, estudiante de Ingeniería de Materiales, UdeA) 
Para mí, la cultura antioqueña se caracteriza por su emprendimiento y fortaleza. Con esto no niego que las otras regiones del país sean importantes; pero pienso que estos ideales nos los enseñan desde la escuela, cuando nos hablan del arriero o campesino paisa echado pa lante, y nosotros lo aprendemos e involucramos [ese concepto] en nuestra vida. (Dana, estudiante de Pedagogía Infantil, UdeA)

En suma, las blanquitudes mestizas o criolizadas implican una forma particular de reconocerse blanco, en términos de apariencia corporal, pero culturalmente reproduce de manera mezclada los valores y prácticas culturales de todos los grupos humanos que habitan los territorios nacionales ya mencionados. Se trata de una construcción híbrida que se originó en el siglo XIX, cuando se creó la ideología del mestizaje con el objetivo de crear identidades nacionales en parte de las Américas y el Caribe (Schwarcz, 1994).

\section{Discusión}

Aunque en Latinoamérica el racismo tiene su génesis en la Colonia, y se fortalece con las ideologías positivistas en los siglos XIX y XX, el racismo contemporáneo —o neorracismo- se construye en historias locales con proyectos nacionales particulares que se enmarcan en políticas neoliberales (Telles, 2014). Actualmente, en países como Brasil y Colombia, el racismo agenciado por las ideas de superioridad racial del blanco sigue siendo un factor importante de desigualdad social y, por tanto, no puede quedar marginado de las agendas nacionales y de las discusiones académicas. En este sentido, los estudios sobre la blanquitud en Latinoamérica tienen como objetivo discutir el papel del blanco en las relaciones racializadas, ya que este rol se tiende a ignorar o naturalizar. La blanquitud ha sido tomada como un punto de vista «neutro» y escasamente se ha racializado. En consecuencia, poco se ha discutido sobre sus efectos, en la actualidad, en las organizaciones colectivas y en la producción de las subjetividades e intersubjetividades.

Así pues, estudios como el presentado en este artículo crean nuevas líneas de investigación en el campo de los estudios étnicos raciales y visibilizan las desigualdades sociales desde un nuevo lente analítico, ya que una de las tareas del trabajo científico en el campo de las ciencias sociales es ayudar a visibilizar aquellas perspectivas de poder que el sentido común ha normalizado, como ha pasado con la blanquitud y sus diferentes tipologías.

Por otro lado, se argumenta que en la actualidad hay que poner el acento en estudios que analicen la blanquitud desde una perspectiva interseccional; es decir, que considere 
no solo la blanquitud como un proyecto de occidentalización, sino también como un indicativo de clase, que permea de manera distinta a los individuos según el sexo u orientación sexual con que se identifiquen. Con este tipo de investigaciones se contribuirá al desmantelamiento y descolonización de las viejas jerarquizaciones sociales, que se sustentan en la invención de la blanquitud eurocéntrica.

El proyecto que alude a la decolonización de la blanquitud implica una alianza política con las blanquitudes críticas y antirracistas, con el propósito de promover movimientos decoloniales autónomos, ya que sin una política decolonial y sin el apoyo académico, no puede haber revolución o cambio social. En palabras de Grosfoguel (2017), «esa revolución decolonial requiere una transformación revolucionaria de la subjetividad, los paradigmas, la ética y las estructuras de dominación» (p. 7). Por lo tanto, cuando se habla de descolonizar la blanquitud no solo se alude al color de piel —eso sería lo de menos-; realmente se trata de una nueva epistemología; se trata de cambiar un modo eurocéntrico de ver, pensar y estar en el mundo (Bouteldja, 2017; Dussel, 2015).

Ahora bien, en el caso de los estudiantes que se identifican con la posición de una blanquitud crítica, resulta evidente que este proyecto reflexivo se podría enmarcar en la descolonización de la blanquitud. De hecho, algunos de ellos hacen parte de grupos estudiantiles que luchan contra las desigualdades de etnicidad y raza, en movimientos que operan en sus respectivas universidades y ciudades (Elena, Ana, estudiantes de UdeA y Thais, estudiante de la UnB). Para ellas, ser blancas o blancas-mestizas no es un impedimento para formar parte de una sociedad más equitativa y crítica. En los casos citados resulta evidente que la educación recibida y los discursos multiculturales han sido claves para la formación de una identidad blanca no esencialista. Aceptar y reproducir prácticas culturales no blancas (como, por ejemplo, reproducir creencias de matriz africana o preferir ciertos tipos de música considerados «negros») contribuye a «positivar» el yo blanco y la alteridad racial y étnica. En el trabajo empírico realizado se encontró que la mayoría de los y las estudiantes se identifican con el polo de una blanquitud crítica (independientemente de su sexo o nacionalidad). Se habla, así, de nuevos paradigmas o modelos de vida, en los que no solo se privilegian las epistemologías blancas, sino también las de los pueblos subalternos en el contexto de las Américas.

Por otro lado, se encontró que los estudiantes brasileños y colombianos interpretan más la blanquitud como un concepto racial o de color de piel que en temimos étnicos. Al parecer, no existe una etnización y una politización cultural blanca, como ocurre con los grupos afrodescendientes o indígenas. Se trata de una blanquitud poco etnizada. No 
obstante, cuando se habla de valores como el emprendimiento, la disciplina, la prosperidad económica y la moralidad cívica o ciudadana, casi siempre estos valores son asociados a personas de color de piel «clara»o «blanca».

Por otra parte, los estudiantes que se identifican con una identidad blanca no crítica, o tendiente a la legitimación de la supremacía blanca como norma cultural y racial, realmente fueron una minoría. Solo en tres estudiantes se identificaron actitudes claramente prejuiciosas en términos raciales y étnicos. No se trata de un racismo directo o violento, sino más bien de una interiorización de prejuicios naturalizados que finalmente terminan afectando la propia subjetividad y la posición de los demás sujetos racializados como negros o indígenas.

En último lugar, se reconoció que la condición de mestizo blanco en Brasil y Colombia es ambigua, ya que, por una parte, las personas que se identifican como mestizas blancas, al reconocer su ascendencia negra o indígena, en el fondo quieren liberarse de la responsabilidad social que implica calificarse de blanco privilegiado (Passos, 2013). Por otro lado, existen personas que reivindican una identidad blanca mestiza de manera positiva y sensible con el diálogo y el discurso multi e intercultural contemporáneo (Urrea et al., 2014). Este tipo de personas, y particularmente de estudiantes, se declararon blancos-mestizos porque consideran que ese es su fenotipo; pero también reconocen y se enorgullecen de tener ascendencia indígena o negra, cuestión que los hace diferentes de los blancos europeos o estadounidenses, pues reivindican una autoidentidad particular.

Como toda investigación, esta tiene limitantes, ya que únicamente se basó en la percepción y en las prácticas de jóvenes estudiantes de universidades públicas. Quizá futuras investigaciones puedan ampliar el espectro analítico y tengan en cuenta a jóvenes no bachilleres o incluso no alfabetizados, con el propósito de encontrar una mayor diversidad discursiva sobre el objeto de estudio. Por tanto, las interpretaciones presentadas aquí no tienen la intención de corresponder a una muestra representativa, en términos estadísticos, sino que se enfocan en los casos analizados, particularmente, en su subjetividad.

\section{Referencias}

Abramo, H., \& Branco, P. (2004). Retratos da juventude brasileira: análises de uma pesquisa nacional. Instituto Cidadania; Fundação Perseu Abramo. 
Alves, L. (2010). Significados de ser branco: a brancura no corpo e para além dele. [Dissertação de mestrado não publicada]. Universidade de São Paulo.

Arango, L. G. (2006). Jóvenes en la universidad: género, clase e identidad profesional. Siglo del Hombre Editores; Universidad Nacional de Colombia.

Baldwin, J. (1984). On being «white» and other lies. Essence.

Bento, M. (Org.) (2003). Psicologia social do racismo: estudos sobre branquitude e branqueamento no Brasil. Vozes.

Bhambra, G. K. (2017). Brexit, Trump, and «methodological whiteness»: On the misrecognition of race and class. The Brithish Journal of Sociology, 68( $\left.\mathrm{S}_{1}\right), \mathrm{S}_{214}-\mathrm{S}_{232}$. https:// doi.org/10.1111/1468-4446.12317

Bonilla-Silva, E. (2015). More than prejudice: Restatement, reflections, and new directions in critical race theory. Sociology of Race and Ethnicity, 1(1), 73-87. https:// doi.org/10.1177/2332649214557042

Bourdieu, P. (1998). La distinción. Taurus.

Bouteldja, H. (2017). Los blancos, los judíos y nosotros: hacia una política del amor revolucionario. Akal.

Cardoso, L. (2010). Branquitude acrítica e crítica: a supremacia racial e o branco antiracista. Revista Latinoamericana de Ciencias Sociales, Niñez y Juventud, 8(1), 607-63o.

Dussel, E. (2015). Filosofías del sur: descolonización y transmodernidad. Akal.

Dyer, R. (1997). White. Routledge.

Echeverría, B. (2007). Imágenes de la «blanquitud». En D. Lizarazo, B. Echeverría, \& P. Lazo (Eds.), Sociedades icónicas: historia, ideología y cultura en la imagen. Siglo XXI.

Fanon, F. (1968). Piel negra, máscaras blancas. Instituto del Libro.

Frankenberg, R. (1993). White women, race matters: The social construction of whiteness. University of Minnesota Press. https://doi.org/10.4324/9780203973431

Frankenberg, R. (2004). A miragem de uma branquitude não marcada. En V. Ware (Org.), Branquidade, identidade branca e multiculturalismo (pp. 307-338). Garamond.

Giménez, G. (2010). Globalización cultural, procesos de interculturación y derechos culturales [Conferencia magistral]. Foro Internacional sobre Multiculturalidad, Guanajuato, México.

Grosfoguel, R. (2008). Hacia um pluriversalismo transmoderno decolonial. Tabula Rasa, (9), 199-2015. https://doi.org/10.25058/20112742.345

Grosfoguel, R. (2017). El manifiesto decolonial de Houria Bouteldja: del grito secular moderno occidental «patria o muerte» a la invocación sagrada «Allahou Akbar». Akal. 
Guerreiro-Ramos, R. A. (1957). Patologia social do «branco» brasileiro. En G. Ramos (Ed.), Introdução crítica à sociologia brasileira (pp. 171-192). Andes Limit.

La entrevista completa de Ilia Calderón con el líder del Ku Klux Klan. (2017, agosto 22).

Semana. https://www.semana.com/nacion/articulo/periodista-de-univision-iliacalderon-entrevisto-al-lider-del-grupo-extremista-del-ku-klux-klan/537238

Loveman, M., \& Muniz, J. (2007). How Puerto Rico became white: Boundary dynamics and intercensus racial reclassification. American Sociological Review, 72(6), 915-939. https://oi.org/10.1177/000312240707200604

Margulis, M., \& Urresti, M. (1998). La construcción social de la condición de juventud. En H. Cubides, M. Laverde, \& C. Valderrama (Eds.), Viviendo a toda: jóvenes, territorios culturales y nuevas sensibilidades (pp. 3-21). Siglo del Hombre Editores; Universidad Central.

McLaren, P. (2005). Impensar la blanquitud y replantear la democracia: hacia un multiculturalismo revolucionario. Siglo XXI.

Melo, J. O. (1988). Historia de Antioquia. Suramericana de Seguros.

Molina-Chávez, W. M., \& Oliva-Figueroa, I. G. (2015). Interfaces complejas en políticas educativas y de juventud: sentidos e identidades. Revista Latinoamericana de Ciencias Sociales, Niñez y Juventud, 13(2), 1125-1140. https://doi.org/10.1160o/1692715x. 13240130114

Montero, L. (2005). Whiteness: factor que explica el fallido proceso de asimilación en los Estados Unidos [Tesis de licenciatura no publicada]. Universidad de las Américas.

Moraes, G., \& Paixão, M. (2014). Mixed and unequal: New perspectives on Brazilian ethnoracial relations. En E. Telles (Ed.), Pigmentocracies: Ethnicity, race and color in Latin America (172-217). The University of North Caroline Press.

Mullings, L. (2013). Interrogando el racismo: hacia una antropología antirracista. Revista CS, (12), 325-375. https://doi.org/10.18046/recs.112.1683

Ortiz-Piedrahíta, V., \& Tavolaro, L. (2015). Reproducción y/o resignificación de las representaciones coloniales sobre la blanquitud en América Latina en los medios de comunicación. En L. Cavalcanti, \& S. Rodrigues-Pinto (Orgs.), América Latina na contemporaneidade: desafios, oportunidades e riscos. CRV.

Passos, A. (2013). Um estudo sobre branquitude no contexto de reconfiguração das relações raciais no Brasil, 2003-2013 [Tese de doutorado não publicada]. Universidade Católica de Rio de Janeiro. 
Piza, E. (2002). Porta de vidro: uma entrada para branquitude. En I. Carone, \& M. A. Bento (Orgs.), Psicologia Social do racismo: estudos sobre branquitude e branqueamento no Brasil (59-90). Vozes.

Quijano, A. (2004). Colonialidad del poder, eurocentrismo y América Latina. Revista Venezolana de Economía y Ciencias Sociales, 1(10), 73-90.

Restrepo, E. (2013). Acciones afirmativas y afrodescendientes en Colombia. En E. Restrepo (Ed.), Estudios afrocolombianos hoy: aportes a un campo transdisciplinario (pp. 249-267). Editorial Universidad del Cauca.

Schucman, L. (2012). Entre o «encardido», o «branco» e o «branquíssimo»: raça, hierarquia e poder na construção da branquitude paulistana [Tese de doutorado não publicada]. Universidade de São Paulo.

Schwarcz, L. (1994). Espetáculo da miscigenação. Estudos Avançados, 8(20), 137-152. http://dx.doi.org/10.159o/So103-40141994000100017

Sovik, L. (2004). Aqui ninguém é branco: hegemonia branca no Brasil. En V. Ware (Org.), Branquidade, identidade branca e multiculturalismo (pp. 363-386). Garamond.

Steyn, M. (2014). Novos matizes da branquidade: a identidade branca numa África do Sul multicultural e democrática. En V. Ware (org.), Branquidade: Identidade branca e multiculturalismo (8-29). Garamond.

Telles, E. (2014). Race and ethnicity in Latin America. En E. Telles (Ed.), Pigmentocracies: Ethnicity, race and color in Latin America. University of North Carolina Press.

Telles, E., \& Flores, R. (2013). Not than just color: Whiteness, nation and status in Latin America. Hispanic American Historical Review, 93(3), 411-449. https://doi.org/ 10.1215/00182168-2210858

Twinang, A. (2015). Purchasing whiteness: Pardos, mulattos, and the quest for social mobility in the Spanish Indies. Stanford University Press.

Uribe, R. (1941). Pueblo antioqueño. Biblioteca Virtual de Antioquia.

Urrea, F., Viveros, M., \& Viáfara, C. (2014). From whitened misegenation to triethnic multiculturalism: Race and ethnicity in Colombia. En E. Telles (Ed.), Pigmentocracies. Ethnicity, race and color in Latin America. The University of North Caroline Press.

Viveros, M. (2010). Imágenes de la masculinidad blanca en Colombia: raza, género y poder político. Universidad Nacional de Colombia.

Wade, P. (1997). Gente negra, nación mestiza: dinámicas en las identidades raciales en Colombia. Editorial Universidad de Antioquia.

Walsh, C. (2007). Interculturalidad y colonialidad del poder: un pensamiento y posicionamiento «otro» desde la diferencia colonial. En S. Castro-Gómez, \& R. Gros- 
foguel (Comps.), El giro decolonial: reflexiones para una diversidad epistémica más allá del capitalismo global. Siglo del Hombre Editores; Universidad Central; Pontificia Universidad Javeriana. Repositorio Universidad Nacional de Salta. http:// www.unsa.edu.ar/histocat/hamoderna/grosfoguelcastrogomez.pdf Ware, V. (2004). Branquidade: Identidade branca e multiculturalismo. Garamond. 